\title{
The effect of artemisinin-combination treatment options on $P$. falciparum gametocyte carriage: a pooled analysis of individual patient data
}

\author{
Georgina Humphreys ${ }^{1,2^{*}}$, WWARN Gametocyte Carriage Study Group ${ }^{1}$ \\ From Challanges in malaria research: Core science and innovation \\ Oxford, UK. 22-24 September 2014
}

\section{Background}

Artemisinin combination therapies (ACT) rapidly clear the asexual parasite population in infected individuals. In addition, the artemisinin components specifically kill early stages of gametocyte development and have an incomplete effect against mature gametocytes. These properties mean that ACT may play a critical role in reducing the transmission of malaria and decreasing the spread of drug resistant parasites. However, different ACT options may have differential effects on gametocyte carriage and the production of gametocytes during infections is influenced by parasite, human and environmental factors.

\section{Material and methods}

A systematic search of the literature was conducted to identify all studies published between 1960 and March 2014, in which patients were enrolled and treated with antimalarials and where gametocyte data were recorded. An a priori data analysis plan was developed to identify factors associated with gametocyte prevalence and density prior to treatment and following treatment with ACT. Individual patient data from over 100 published studies ( $\mathrm{n}>50,000$ ) were collated, curated and included in the analysis, with data from 21 African and 6 Asian countries. Criteria for the quality of gametocyte assessments were ascribed to the various studies.

\section{Results}

Before September 2014, we will have determined the effects of asexual parasite density, age, transmission intensity and haemoglobin concentration on enrolment gametocyte prevalence and density. We will further present

WorldWide Antimalarial Resistance Network (WWARN), Oxford, UK Full list of author information is available at the end of the article

๑ 2014 Humphreys and WWARN Gametocyte Carriage Study Group; licensee BioMed Central Ltd. This is an Open Access article distributed under the terms of the Creative Commons Attribution License (http://creativecommons.org/licenses/by/4.0), which Commons Public Domain Dedication waiver (http://creativecommons.org/publicdomain/zero/1.0/) applies to the data made available
Cite this article as: Humphreys and : The effect of artemisinin-

combination treatment options on $P$. falciparum gametocyte carriage: a pooled analysis of individual patient data. Malaria Journal 2014 13(Suppl 1):P44.

Submit your next manuscript to BioMed Central and take full advantage of:

- Convenient online submission

- Thorough peer review

- No space constraints or color figure charges

- Immediate publication on acceptance

- Inclusion in PubMed, CAS, Scopus and Google Scholar

- Research which is freely available for redistribution in this article, unless otherwise stated. \\ () Biomed Central}

